\title{
Palliative Care of the Patient with Dementia
}

Raja Malhi, MD; ${ }^{1}$ Jennifer McElveen, DNP; ${ }^{2}$ Linsey O’Donnell, DO $^{3}$

1. Physician, Supportive and Palliative Care, ChristianaCare

2. Lead Nurse Practitioner, Outpatient Supportive and Palliative Care, ChristianaCare

3. Clinical Lead, Outpatient Supportive and Palliative Care Program, ChristianaCare; Clinical Assistant Professor, Sidney Kimmel Medical College, Thomas Jefferson University; Clinical Assistant Professor, Philadelphia College of Osteopathic Medicine

\section{Introduction to Palliative Care}

Palliative care is medical care that focuses on the relief of the symptoms and physical and mental stress of living with a serious illness. It can be provided alongside curative therapies at any stage of illness. ${ }^{1}$ Palliative care can identify problematic symptoms and provide better symptom management and quality of life compared to usual care. ${ }^{2-4}$ Studies show positive benefits including better symptom control, including mood and quality of life increased attention to caregiver needs, feeling more in control, as well as having decreased costs with improved utilization of health care resources. ${ }^{5}$ Numerous medical organizations include provision of palliative care as a best practice including the American College of Cardiology and American Heart Association guidelines for Advanced Heart Failure ${ }^{6}$ and the American Society of Clinical Oncology. ${ }^{7}$

The palliative care team typically includes physicians, advanced practice providers (physician assistants and nurse practitioners), nurses, social workers, and chaplain services, though the team can take many forms. For example, the physician may provide medications to treat pain, dyspnea, or other symptoms, while the patient is supported in psychosocial needs by social work, and spiritual needs by the chaplain. This team model provides exceptional care addressing a whole-person approach and offering a unique framework to address the many domains that can impact quality of life and cause suffering. Practically, the team hopes to provide expert treatment of symptoms of serious illness, complex communication, provide open discussion about treatment choices and advance care planning, while providing an extra layer of support working with other health care providers to support the patient and family physically, emotionally and spiritually.

\section{Brief Overview of Dementia}

Dementia is a major health problem affecting approximately 47 million people worldwide, and by 2050 , the number is expected to increase to 131 million. ${ }^{8}$ Dementia is common yet under recognized public health problem in United States. The prevalence of dementia is around $15 \%$ in people older than 68 years. Alzheimer's Disease is the most common cause of dementia and accounts for approximately 5.8 million cases. This number is projected to increase to around 13.8 million by the year $2050 .^{9}$

Alzheimer's Disease is the sixth leading cause of death and the fifth leading cause among people older than 65 years. ${ }^{9}$ There are several other causes of dementia (see Table 1). 
Dementia not only affects the physical and cognitive functions, but also takes toll on the psychological, social, spiritual and financial aspects of patients and their loved ones. Average total cost per decedent for dementia $(\$ 287,038)$ was significantly greater than for those who died of heart disease $(\$ 175,136)$, cancer $(\$ 173,383)$, or other causes $(\$ 197,286)$. While Medicare expenditures were similar across groups, average out-of-pocket spending for dementia patients $(\$ 61,522)$ was $81 \%$ higher than for non-dementia patients $(\$ 34,068) .{ }^{10}$

Table 1. Causes of Dementia

\begin{tabular}{|l|l|}
\hline 1.) Alzheimer's Disease & Most common cause. Caused by plaque build-up in the brain. \\
\hline 2.) Vascular Dementia & Caused by damage to the vessels that supply blood to the brain. \\
\hline 3.) Lewy Body Dementia & Caused by balloon like clumps of protein deposit in brain. \\
\hline $\begin{array}{l}\text { 4.) Frontotemporal } \\
\text { Dementia }\end{array}$ & $\begin{array}{l}\text { Caused by breakdown of nerves and cells in frontal and temporal } \\
\text { part of brain. }\end{array}$ \\
\hline 5.) Mixed Dementia & Caused by combination of several causes listed above \\
\hline $\begin{array}{l}\text { 6.) Disorders linked to } \\
\text { Dementia: }\end{array}$ & $\begin{array}{l}\text { Huntington Disease: genetic mutation causes nerve cell } \\
\text { breakdown } \\
\text { Traumatic Brain Injury: results from repeated head trauma } \\
\text { Creutzfeldt- Jacob Disease: depositions of infectious prion } \\
\text { proteins } \\
\text { Parkinson's Disease: people with advanced disease develop } \\
\text { dementia }\end{array}$ \\
\hline
\end{tabular}

There are several risk factors that contribute to development of dementia. Age and positive family history of dementia are the two most common identifiable risk factors.

Non-modifiable risk factors include:

- Age. Risk rises with age, especially after 65;

- Family History. A positive family history puts an individual at a higher risk for developing dementia; and

- Down Syndrome. Many people with Down Syndrome develop early onset dementia.

Modifiable risk factors for dementia include:

- Diet and Exercise. Lack of exercise and unhealthy diet increase risk.

- Alcohol Intake. Excessive alcohol intake linked with early onset dementia.

- Diabetes Mellitus. Poorly controlled diabetes increases risk of dementia.

- Smoking. Increases chance of blood vessel disease and dementia.

- Air Pollution. Traffic exhaust and burning wood have been linked with dementia.

- Head Trauma.

- Sleep Disturbance. People with sleep apnea have a higher risk for dementia.

- Vitamin Deficiencies. Low levels of vitamins B6, B12, D and folate can increase the risk of dementia. 


\section{FAST Scale}

The Functional Assessment Staging Tool (FAST) is a scale that was developed by Dr. Barry Reisberg, a leader in Alzheimer's Disease. This scale primarily focuses on a person's functional status and ability to perform activities of daily living. The FAST scale is divided into seven distinct levels ${ }^{11}$ :

1. Normally Functioning Adult: free of cognitive and functional decline

2. Normally Functioning Senior Adult: complaints of forgetfulness and misplacing items

3. Early Dementia: individuals demonstrate subtle signs of mild cognitive impairment that may only be noticeable to close friends and family. Concentration becomes difficult. This stage can last 2-7 years.

4. Mild Dementia: this is when most are diagnosed with dementia. Signs of cognitive impairment become evident. There is increased difficulty with paying bills or preparing meals. Major or recent events are often forgotten. This stage can last an average of two years.

5. Mid-Stage Dementia: this person can no longer live alone. At this stage, there may be issues with wandering, hallucinations, and confusion. Stage 5 and 6 can last approximately four years.

6. Moderately Severe Dementia: person becomes dependent in their care and require assistance $24 \mathrm{hrs}$ a day. This stage is broken down into sub-stages:
A. Need assistance with dressing
B. Unable to bathe properly
C. Difficulty with toileting themselves
D. Urinary incontinence, occasionally
E. Bowel incontinence, occasionally

7. Severe (End Stages) of Dementia: this is the stage when the body is shutting down and death is in the near future, likely within 2.5 years. This stage is broken down into sub-stages.
A. Speech becomes limited to half a dozen words.
B. Speech is limited to one word or less.
C. The ability to ambulate independently is lost.
D. Unable to sit up without assistance.
E. Ability to smile is lost.
F. Ability to hold head up independently is lost.

\section{Dying with Dementia or Dying from Dementia}

Dementia care has improved over the last few decades, however many patients and families still lack significant understanding of the disease. Population based studies estimate that 600,000 
Americans with Alzheimer's disease died in 2010. ${ }^{12}$ The median survival after diagnosis of dementia ranges from 3 to 12 years. ${ }^{13}$ The majority of these patients spent a significant time in the advanced stage of dementia and were confined in nursing homes at the time of the time of their death. ${ }^{14}$

There has been significant literature to support that dementia itself is a terminal illness, however this fact continues to remain understated. The terminal effects of advanced dementia were described in the Choices, Attitudes, and Strategies for Care of Advanced Dementia at End of Life (CASCADE) study. This study prospective followed 323 nursing home residents with advanced dementia for 18 months. This study corroborated the prior research showing high mortality rates among patients with advanced dementia. ${ }^{15}$ With a six month mortality rate of $25 \%$ and median survival of 1.3 years, advanced dementia is associated with life expectancy similar to commonly recognized terminal conditions such as congestive heart failure and metastatic breast cancer. Most common clinical complications were eating problems, febrile episodes and pneumonia. ${ }^{16}$

In addition to the common complications many patients with advanced dementia also experience several other distressing symptoms such as dyspnea, pain, pressure ulcers, agitation, and aspiration.

\section{Anticipatory Palliative Care Guidance for Patients with Dementia}

As dementia worsens, the majority of the decision-making responsibility is left to the health care proxies. These decisions can be challenging and take an emotional toll. In a prospective study, more than $90 \%$ of the proxies stated that the goal of care was comfort. ${ }^{16}$ The cornerstone of care of patients with advanced dementia is advance care planning.

Advance care planning should start early on in the disease process when the patient is still able to participate in the decision-making process. The first step should be filling out a written advance directive and choosing an appropriate surrogate decision maker. Getting Palliative Care involved early in the disease trajectory has also been shown to have a positive effect on many clinical outcomes. Early referral to palliative care services was associated with more inpatient hospice utilization, prevention of overly aggressive treatments, and improved comfort and quality of life for persons with dementia and their families. ${ }^{17}$

Planning for an uncertain future can be challenging. Our role as palliative care providers is to educate the patients and their families about the disease trajectory and the expected complications. Treatment decisions for patients with advanced dementia should be guided by the patient's wishes and goals of care. Keeping the patient's best interest in mind, the health care providers and patient's health care proxies must make shared decisions. For tips regarding advance care planning see Table 2 .

Table 2. Tips for Advance Care Planning

\begin{tabular}{|l|l|}
\hline Start early & Ideally before patient loses decision making capacity \\
\hline Establish directives & $\begin{array}{l}\text { Preferably in writing. } \\
\text { Appoint a health care proxy. } \\
\text { Establish preferred goals of care. }\end{array}$ \\
\hline
\end{tabular}




\begin{tabular}{|l|l|}
\hline $\begin{array}{l}\text { Have conversations } \\
\text { about disease } \\
\text { trajectory }\end{array}$ & $\begin{array}{l}\text { Continue conversations between health care proxies and } \\
\text { providers regarding what to expect as dementia progresses. } \\
\text { Learn about dementia as a terminal illness (i.e.: expect loss of } \\
\text { basic bodily functions such as ability to swallow and fight } \\
\text { infections). }\end{array}$ \\
\hline $\begin{array}{l}\text { Discuss treatment } \\
\text { preferences. } \\
\text { Consider the use of } \\
\text { structured } \\
\text { conversation guides }\end{array}$ & $\begin{array}{l}\text { Preferably before complications arise. } \\
\text { Discuss treatment choices regarding specific clinical } \\
\text { problems (cardiopulmonary resuscitation, artificial nutrition, } \\
\text { mechanical ventilation). } \\
\text { Have conversations with health care providers regarding } \\
\text { advantages and disadvantages of options based on evidence- } \\
\text { based medicine. } \\
\text { Align treatment options with established goals of care. }\end{array}$ \\
\hline $\begin{array}{l}\text { Review directives and } \\
\text { treatment options } \\
\text { periodically }\end{array}$ & $\begin{array}{l}\text { Review periodically or whenever there is a change in health } \\
\text { status. } \\
\text { Update document(s) with any revisions to goals of care or } \\
\text { treatment preferences. }\end{array}$ \\
\hline
\end{tabular}

\section{Common Palliative Symptom Management Issues in Palliative Care}

Palliative care focusing on quality of life for people with advanced dementia can improve symptom burden, prevent under treatment of symptoms and overtreatment with unnecessary and burdensome treatment, and can also reduce caregiver burden and enhance caregiver quality of life. ${ }^{18}$ Some of the distressing symptoms that Palliative Care can assist with are agitation, swallowing difficulties, pain, and hallucinations.

\section{Agitation}

Agitation is common in Alzheimer's Dementia (AD) and other dementias and has a significant impact on caregivers. Agitation is related to the severity of dementia and to specific types of associated psychopathology implicating frontal lobe dysfunction. Agitation can occur frequently and can be a distressing symptom. This symptom is disturbing for the individuals with Alzheimer Disease, may confer risk to the patient and others, and present a major management challenge for primary clinicians. A study conducted by Senanarong V, et al., is the largest and most comprehensive assessment of agitation reported. The data suggest that agitation in AD is a frontal lobe syndrome. Frontal lobe dysfunction may predispose AD patients to agitation by exaggerating behavioral responses to many types of coexisting psychopathology or environmental provocations. ${ }^{19}$

Agitation can take on many forms, such as wandering, crying out, and aggression. There are several reasons a person may be agitated, such as pain, stress, lack of sleep, constipation, and many other factors. It is presumed to cause distress to the individual and an increase in caregiver burden. Psychosocial support, non-pharmacological management, and pharmacological management might all be necessary to assist through this person's trajectory. Assisting families with methods to manage the agitation and support their loved one can provide considerable relief to the caregivers. Examples of methods could include speaking calmly, playing soothing music, taking walks, distracting with enjoyed activities, and maintaining a daily routine. Educating the 
family on safety concerns is just as important. There may be times when they must protect themselves or call for assistance when there is a potentially dangerous situation.

\section{Swallowing Difficulties}

According to Goldberg and Altman, dementia is the leading cause of death in the US, with mortality affected by aspiration, hydration, and nutritional status. The rate of patients being diagnosed with dementia is growing rapidly. The prevalence is estimated to double every five years after 65 years old, and at age 85 years, the prevalence is approximately $50 \% .{ }^{20}$ When a patient with advanced Alzheimer's Disease reaches the last six months to a year of their lives, they will likely have difficulty with eating and swallowing. This is a normal progression of their disease process. It is also a difficult time for the patients, their families, physicians, and nurses. There is a false belief or optimism that artificial nutrition improves nutrition, therefore it improves quality of life. Despite the numerous evidence-based studies that are available, artificial nutrition continues to be the primary recommendation.

Due to the progression of the disease and poor appetite, the individual begins to lose weight. This is a very distressing and overwhelming time for the caregiver. The caregiver may feel like a failure, and that they are not providing adequate care due to their loved one's decline. Unfortunately, there will come a time when frequent coughing, increased congestion, shortness of breath, and possibly a fever will lead to a trip to the hospital. Due to the lack of understanding of the progression of dementia, some providers will recommend starting artificial nutrition via a percutaneous gastrostomy (PEG) tube when poor nutrition and/or dysphagia becomes an issue. According to the American Geriatric Society, feeding tubes are not recommended for older adults with advanced dementia.

Artificial nutrition in people with advanced dementia does not prevent aspiration pneumonia, reduce the risk of pressure ulcer development or infection, improve functional status, prevent and/or reduce the consequences of malnutrition, provide comfort and palliation, or reduce mortality". ${ }^{21}$

In all actuality, feeding tubes can cause pain, infection, or bleeding at the site of the tube; increase aspiration risk; will not heal pressure ulcers, diarrhea, constipation, reflux, fluid overload or upper airway secretions in patients with heart or lung disease; and may cause a person to need to be restrained to prevent them from pulling the tube out. ${ }^{22}$ Placing a PEG tube for artificial nutrition is a medical procedure. It has not been found to increase mortality or quality of life in patients with end stage dementia. The number of patients living with dementia is growing and so are the number of peg tube placements. In a study conducted by Teno et al., it was found that the type of attending physician influenced whether or not a peg feeding tube was inserted during that hospitalization. ${ }^{23}$ This study also recommended that hospitals should educate healthcare providers on the lack of efficacy of PEG feeding tubes in persons with advanced dementia.

When a person living with advanced dementia loses the desire to eat, the family also experiences a loss. Careful hand feeding has been proven to be the best and safest way to provide nutrition to a person at the end of their lives. Comfort feeding encourages human contact and maximizes quality of life. ${ }^{24}$ Following the person's cues on what they can and cannot tolerate will be the most beneficial. Spending that time with them to bond and enjoy their company is what increases 
quality of life. Initiating palliative care services early in the care of these patients can assist with psychosocial support and advance care planning. It is important that goals of care conversations take place when the individual is still able to participate. These discussions allow the person to make their wishes known concerning their health care choices prior to losing the ability to participate in their care. Education, advance care planning, and communication are key to assisting patients living with advanced dementia to achieve the best quality of life.

\section{Pain}

In their last 6-12 months of the life, people living with dementia most often suffer from restrictions in mobility and pain. Decreased mobility leads to stiffness, achy joints/arthritis, pressure ulcers, and infections such as pneumonia and urinary tract infections. Many people with advanced dementia experience pain; it is one of the most common symptoms and persists over the course of disease. ${ }^{25}$ Untreated pain can present as depression, agitation, and challenging behavior due to a person's inability to express the source of their pain. Pain is subjective, yet patients with dementia are limited when it comes to self-reporting their pain. Communication restrictions and restrictions in memory and executive function hinder the person in communication of their pain. ${ }^{25}$ The Pain Assessment in Advanced Dementia (PAINAD) scale is a frequently used tool. It evaluates behavioral categories breathing, vocalization, facial expression, body language, and consolability as indicators of pain. Behavior is more correctly interpreted if the caregiver knows the person with dementia well and over a longer period of time.

Non-pharmacological interventions may be used to relieve pain, such as massages, passive range of motion, application of heat, or ice. Relaxation techniques, decreased stimulation, music, naps, or the presences of someone they trust can be extremely helpful. Pharmacological intervention such as analgesics may be needed at times. They are most beneficial if the source can be identified and treated appropriately. Often, primary care providers are not comfortable with treating pain at the end of a person's life, and they will refer to palliative care. Palliative care providers specialize in identifying the source of discomfort and treat appropriately to prevent under or over treatment. Education to the family is also a priority which increases their comfort level on caring for their loved one.

\section{Caregiver Experience and Palliative Support}

People living with advanced dementia are usually cared for by a family member, spouse, sibling, or adult children. Being the caregiver of a person with dementia can be extremely burdensome. Family members report being stressed, having anxiety, have feelings of being restricted, and having a poor quality of life. Through our experience with this population, we have observed many caregivers wanting to keep their family member home and not place them in a facility out of a sense of guilt. There is a sense of being a failure if they must resort to placement of their loved one. The sense of guilt may stem from making a decision you know is against your love ones wishes. $^{26}$

Caregivers need a significant amount of support to assist them in caring for their loved one. They may begin having their own struggles with anxiety and depression. Grieving and a sense of loss begin long before the person actually passes away. It can start with the loss of personality or recognizing family members. Education on what to expect is not usually provided with routine physician follow-up. Studies looking at the needs of caregivers have shown that emotional and 
social support, improving coping strategies, and providing information about the illness and available support services can help reduce caregiver burden. ${ }^{27}$

A palliative care team is critical to the caregiver for education, support, and walking with them through this loss. Having the availability of clinicians, nurses, social workers, and chaplains can assist in improving their quality of life.

\section{End Stage Dementia and the Hospice Transition}

Dementia is a life limiting illness. While sometimes not thought of as a terminal illness, patients with advanced dementia may eventually die of consequences of the disease including pneumonia, eating problems, or febrile illness. ${ }^{16}$ Individuals can live with dementia for many years, which can make counseling regarding the end of life particularly difficult.

Hospice is a program, often offered as a Medicare benefit, which provides medical care focused towards comfort and quality of life in the last six months of life, if the disease takes its usual course. ${ }^{28}$ An increasing number of people with dementia are enrolling with hospice at the end of life, representing the fastest growing group of hospice users. ${ }^{29}$

Hospice provides a constellation of clinical and psychosocial supports to patients at the end of life including the services of an interdisciplinary team including physicians, nursing care, home health aides, spiritual and emotional support as well as other medical professionals. Hospice also provides medical equipment and supplies, and medications, that are related to the hospice diagnosis. Patients can access care in the home, and during short term inpatient stays for symptom management and respite care. Caregivers can expect bereavement support before and after the patient's death. ${ }^{28}$

Hospice admission criteria typically uses the FAST score to determine a prognosis of six months or less in patients with dementia. The FAST score is a standardized scale that allows for assessment of functional changes throughout the course of Alzheimer's disease. ${ }^{30}$ FAST Stage $7 \mathrm{C}$ is defined by the loss of the ability to walk independently with presence of limited speech (speech is limited to a half dozen or fewer intelligible and different words). At this stage, survival is often six months or less and patients are hospice appropriate. ${ }^{31}$

According to Medicare guidelines, in addition to being at least Stage 7 or beyond on the FAST scale, the occurrence of at least one of the following medical complications in the prior year indicates hospice eligibility:

- Aspiration pneumonia,

- Pyelonephritis,

- Septicemia,

- Multiple decubitus ulcers greater than or equal to stage 3,

- Recurrent fever after antibiotics,

- Inability to maintain sufficient fluid and calorie intake with $10 \%$ weight loss in previous six months, or

- Serum albumen $<2.5 \mathrm{~g} / \mathrm{dL}$. 
Other factors to suggest a decline in this time frame include numerous symptoms, signs, lab values and comorbidities that can be referenced on the CMS.gov website.

Studies have found hospice benefits for patients with advanced dementia include a lower probability of hospitalization during last 30 days of life, ${ }^{32}$ high probability of routine treatment of daily pain, ${ }^{33}$ and greater patient and caregiver satisfaction with care over a usual care group. ${ }^{34}$

Whether providing primary care, specialist care or specialty level palliative care, patients living with dementia should regularly be evaluated as to whether they are at the stage where hospice will benefit them and their caregivers. As a clinical best practice, this evaluation should be done with changes in status, hospitalizations or periodically during routine follow up visits.

\section{Obstacles to Adoption of Palliative Care}

Palliative care is one of the newest medical specialties certified by the Accreditation Council for Graduate Medical Education (ACGME) and was recognized as a medical sub-specialty in the US in 2006. As a field it is still growing and expanding its base of evidence and research. Recent studies of palliative care show that it provides a high value service to patients and families and new research is being done all the time, from cancer to Parkinson's disease to cystic fibrosis. We are learning more all the time about how best to integrate palliative care principles into the care of patients with serious illness.

In contrast to palliative care, hospice services are more widely known. The beginnings of what eventually became hospice care was developed by Dame Cicely Saunders in the UK in the 1960s. The US hospice benefit was authorized by the Tax Equity and Fiscal Responsibility Act (TEFRA) of $1982 .{ }^{35}$

The World Health Organization cites worldwide barriers to adoption of palliative care. These include national health policies and systems that do not include palliative care. ${ }^{36}$ In the US, despite the presence of the Medicare hospice benefit, palliative care is typically provided as a fee-for-service program. There are alternate payment models proposed and functioning including contracted rate, per-member-per-month, and accountable care organization shared savings programs ${ }^{37}$ Fee-for-service can be a particularly difficult model given the palliative care focus on the interdisciplinary team and lacking payment models that match the service delivered.

Other barriers include a lack of awareness among policy-makers, health professionals, and the public regarding palliative care and the benefits it provides, as well as cultural and social barriers around death and dying, and misconceptions including that palliative care is only for dying patents. ${ }^{38}$ Our team faces challenges every day, dispelling rumors and educating patients, colleagues and caregivers about palliative care. Sometimes medical teams worry that mentioning palliative care or hospice may cause a patient to lose hope, rather than reframing that it is equally acceptable to hope for better symptom control and understanding of a patient's illness.

Prognostication in general, and recognition of the right time to refer to hospice and palliative care services, can be very difficult. A seminal research study found that physicians would provide a frank prognostic estimate to cancer patients $375 \%$ of the time, with the remaining time providing a conscious over or underestimate. ${ }^{39}$ It is also difficult for a patient's surrogates to understand of their prognosis. Recent research demonstrates that when asked to respond to hypothetical prognostic discussions, surrogates with relatives in intensive care were more likely to correctly interpret optimistic predictions rather than pessimistic ones. ${ }^{40}$ 
An additional roadblock to adoption of specialty level palliative care services into usual medical care is that these conversations take time. From introducing a palliative care referral, to the time it takes for the palliative care physician or team member to do a full symptom assessment and goals of care discussion, these are complex and nuanced conversations.

\section{Palliative Care in the State of Delaware}

Delaware is a small state, and as such, there is a unique ability for health systems, care providers, and palliative care and hospice teams to work together to improve care of the seriously ill.

One example of that process in action was the development, in conjunction with the State legislature, of the DMOST: Delaware Medical Orders for Scope of Treatment. This is an essential document that provides an actionable medical order for treatment choices at the end of life. $^{41}$

In 2011, the Center for Advancement of Palliative Care (CAPC) surveyed all states for access to in-hospital palliative care. Only two states received an " $F$ " rating: Delaware and Mississippi. Thanks to work at the State and hospital level, in 2019 CAPC re-surveyed the states and Delaware was one of only four states with $100 \%$ access to palliative care, with a palliative care team represented in all hospitals. This is a key metric that Delaware must work to maintain, and demonstrates significant growth and understanding regarding the importance of palliative care. ${ }^{42}$

Similarly to the expansion of palliative care in hospitals throughout the past decades, palliative care is now also growing in community settings. Our service has embedded teams at ChristianaCare in the Helen F. Graham Cancer Center, Advanced Heart Failure Clinic, Cystic Fibrosis Clinic, and Primary Care, and has developed an In-Home program. Expansion into the community places palliative care where patients are, and where they feel most comfortable. However, this shift and growth requires ongoing education to not only the public, but also to the outpatient medical system.

This education process is supported by numerous stakeholders, from providers who have had excellent experiences with palliative care, to hospices, and health systems. One unique opportunity for some of the palliative care programs in the state came this year when the eBright Health Accountable Care Organization chose access to palliative care as a key metric to improve the health of their seriously ill population.

As much as specialty level palliative care is growing, the number of palliative care providers is limited, and there will never be enough of us to meet all of the palliative care needs of our communities. As such, one of our strategic initiatives is to educate and train all care providers in the delivery of primary palliative care: basic symptom management, goals of care and communication strategies, and advance care planning. Only by working together can we ensure our patients and their families have the respectful care that they deserve.

On the individual level, we encourage all health care providers in all fields, providers and support staff alike, to expand their knowledge about palliative care principles. Our team, and may other teams around the state, offer regular education opportunities.

On a national level we encourage our Senators and Representatives to support expansion of the palliative care workforce by passing the Palliative Care and Hospice Education and Training act (PCHETA) and expanding Medicare-funded graduate medical education (GME) slots to train medical professionals with provisions included for palliative care fellowships. 
In conclusion, while palliative care may not change the course of serious illness, access to high quality palliative care can change the experience of living with serious illness by controlling symptoms, and empowering patients and families to make choices that help them live as well as possible.

\section{References:}

1. World Health Organization. (2020, Jun 19). WHO definition of palliative care. Retrieved from: https:/www.who.int/cancer/palliative/definition/en/

2. Kelley, A. S., \& Morrison, R. S. (2015, August 20). Palliative care for the seriously ill. The New England Journal of Medicine, 373(8), 747-755. PubMed https://doi.org/10.1056/NEJMra1404684

3. Modonesi, C., Scarpi, E., Maltoni, M., Derni, S., Fabbri, L., Martini, F., . . . Amadori, D. (2005, October). Impact of palliative care unit admission on symptom control evaluated by the edmonton symptom assessment system. Journal of Pain and Symptom Management, 30(4), 367-373. PubMed https://doi.org/10.1016/j.jpainsymman.2005.04.007

4. Potter, J., Hami, F., Bryan, T., \& Quigley, C. (2003, June). Symptoms in 400 patients referred to palliative care services: Prevalence and patterns. Palliative Medicine, 17(4), 310314. PubMed https://doi.org/10.1191/0269216303pm760oa

5. Kavalieratos, D., Corbelli, J., Zhang, D., Dionne-Odom, J. N., Ernecoff, N. C., Hanmer, J., . . Schenker, Y. (2016, November 22). Association between palliative care and patient and caregiver outcomes: A systematic review and meta-analysis. JAMA, 316(20), 2104-2114. PubMed https://doi.org/10.1001/jama.2016.16840

6. Hunt, S. A., Abraham, W. T., Chin, M. H., Feldman, A. M., Francis, G. S., Ganiats, T. G., . . .. Riegel, B., \& the American College of Cardiology, \& the American Heart Association Task Force on Practice Guidelines, \& the American College of Chest Physicians, \& the International Society for Heart and Lung Transplantation, \& the Heart Rhythm Society. (2005, September 20). ACC/AHA 2005 guideline update for the diagnosis and management of chronic heart failure in the adult. Circulation, 112(12), e154-e235. PubMed

7. Ferrell, B. R., Temel, J. S., Temin, S., \& Smith, T. J. (2017, February). Integration of palliative care into standard oncology care: ASCO clinical practice guideline update summary. J Oncol Pract, 13(2), 119-121. PubMed https://doi.org/10.1200/JOP.2016.017897

8. Arvanitakis, Z., Shah, R. C., \& Bennett, D. A. (2019, October 22). Diagnosis and management of dementia [review]. JAMA, 322(16), 1589-1599. PubMed https://doi.org/10.1001/jama.2019.4782

9. Goodman, R. A., Lochner, K. A., Thambisetty, M., Wingo, T. S., Posner, S. F., \& Ling, S. M. (2017, January). Prevalence of dementia subtypes in United States Medicare fee-forservice beneficiaries, 2011-2013. Alzheimers Dement, 13(1), 28-37. PubMed https://doi.org/10.1016/j.jalz.2016.04.002

10. Kelley, A. S., McGarry, K., Gorges, R., \& Skinner, J. S. (2015, November 17). The burden of health care costs for patients with dementia in the last 5 years of life. Annals of Internal Medicine, 163(10), 729-736. PubMed https://doi.org/10.7326/M15-0381 
Doi: $10.32481 /$ djph.2021.09.012

11. Dementia Care Central. (2020, April.) Stages of Alzheimer's \& dementia: durations \& scales used to measure progression (GDS, FAST \& CDR). Retrieved from https://www.dementiacarecentral.com/aboutdementia/facts/stages/

12. Weuve, J., Hebert, L. E., Scherr, P. A., \& Evans, D. A. (2014, March). Deaths in the United States among persons with Alzheimer's disease (2010-2050). Alzheimers Dement, 10(2), e40-e46. PubMed https://doi.org/10.1016/j.jalz.2014.01.004

13. Todd, S., Barr, S., Roberts, M., \& Passmore, A. P. (2013, November). Survival in dementia and predictors of mortality: A review. International Journal of Geriatric Psychiatry, 28(11), 1109-1124. PubMed https://doi.org/10.1002/gps.3946

14. Arrighi, H. M., Neumann, P. J., Lieberburg, I. M., \& Townsend, R. J. (2010, JanuaryMarch). Lethality of Alzheimer disease and its impact on nursing home placement. Alzheimer Disease and Associated Disorders, 24(1), 90-95. PubMed https://doi.org/10.1097/WAD.0b013e31819fe7d1

15. Meier, D. E., Ahronheim, J. C., Morris, J., Baskin-Lyons, S., \& Morrison, R. S. (2001, February 26). High short-term mortality in hospitalized patients with advanced dementia: Lack of benefit of tube feeding. Archives of Internal Medicine, 161(4), 594-599. PubMed https://doi.org/10.1001/archinte.161.4.594

16. Mitchell, S. L., Teno, J. M., Kiely, D. K., Shaffer, M. L., Jones, R. N., Prigerson, H. G., . . Hamel, M. B. (2009, October 15). The clinical course of advanced dementia. The New England Journal of Medicine, 361(16), 1529-1538. PubMed https://doi.org/10.1056/NEJMoa0902234

17. Amano, K., Morita, T., Tatara, R., Katayama, H., Uno, T., \& Takagi, I. (2015, March). Association between early palliative care referrals, inpatient hospice utilization, and aggressiveness of care at the end of life. Journal of Palliative Medicine, 18(3), 270-273. PubMed https://doi.org/10.1089/jpm.2014.0132

18. Eisenmann, Y., Golla, H., Schmidt, H., Voltz, R., \& Perrar, K. M. (2020, July 21). Palliative care in advanced dementia. Frontiers in Psychiatry, 11, 699. PubMed https://doi.org/10.3389/fpsyt.2020.00699

19. Senanarong, V., Cummings, J. L., Fairbanks, L., Mega, M., Masterman, D. M., O’Connor, S. M., \& Strickland, T. L. (2004). Agitation in Alzheimer's disease is a manifestation of frontal lobe dysfunction. Dementia and Geriatric Cognitive Disorders, 17(1-2), 14-20. PubMed https://doi.org/10.1159/000074080

20. Goldberg, L. S., \& Altman, K. W. (2014, October 14). The role of gastrostomy tube placement in advanced dementia with dysphagia: A critical review. Clinical Interventions in Aging, 9, 1733-1739. PubMed https://doi.org/10.2147/CIA.S53153

21. American Geriatrics Society Ethics Committee and Clinical Practice and Models of Care Committee. (2014, August). American Geriatrics Society feeding tubes in advanced dementia position statement. Journal of the American Geriatrics Society, 62(8), 1590-1593. PubMed https://doi.org/10.1111/jgs.12924

22. Ying, I. (2015, March). Artificial nutrition and hydration in advanced dementia. Can Fam Physician, 61(3), 245-248, e125-e128. PubMed 
23. Teno, J., Meltzer, D., Mitchell, S., Fulton, A. T., Gozalo, P., \& Mor, V. (2014). The role of physician specialty and severely demented hospitalized nursing home residents' peg feeding tube insertion. Health Affairs (Project Hope), 33(4), 675-682. PubMed https://doi.org/10.1377/hlthaff.2013.1248

24. Heuberger, R. A. (2010, October). Artificial nutrition and hydration at the end of life. Journal of Nutrition for the Elderly, 29(4), 347-385. PubMed https://doi.org/10.1080/01639366.2010.521020

25. Eisenmann, Y., Golla, H., Schmidt, H., Voltz, R., \& Perrar, K. M. (2020, Jul). Palliative care in advanced dementia. 11, 699. Doi

26. Alzheimer's Association. Greater Missouri Chapter. (2017). Guilt and grief when moving your loved one to a care facility. Retrieved from https://www.alz.org/media/greatermissouri/guilt_and_grief_when_moving_your_loved_one _to_a_care_facility.pdf

27. Birkenhäger-Gillesse, E. G., Achterberg, W. P., Janus, S. I. M., Kollen, B. J., \& Zuidema, S. U. (2020, November). Effects of caregiver dementia training in caregiver-patient dyads: A randomized controlled study. International Journal of Geriatric Psychiatry, 35(11), 13761384. PubMed https://doi.org/10.1002/gps.5378

28. Centers for Medicare \& Medicaid Services. (n.d.). Hospice. Retrieved from https://www.cms.gov/Medicare/Medicare-Fee-for-Service-Payment/Hospice

29. Aldridge, M. D., Canavan, M., Cherlin, E., \& Bradley, E. H. (2015, January). Has hospice use changed? 2000-2010 utilization patterns. Medical Care, 53(1), 95-101. PubMed https://doi.org/10.1097/MLR.0000000000000256

30. Sclan, S. G., \& Reisberg, B. (1992). Functional assessment staging (FAST) in Alzheimer's disease: Reliability, validity, and ordinality. International Psychogeriatrics, 4(Suppl 1), 5569. PubMed https://doi.org/10.1017/S1041610292001157

31. Brown, M. A., Sampson, E. L., Jones, L., \& Barron, A. M. (2013, May). Prognostic indicators of 6-month mortality in elderly people with advanced dementia: A systematic review. Palliative Medicine, 27(5), 389-400. PubMed https://doi.org/10.1177/0269216312465649

32. Miller, S. C., Gozalo, P., \& Mor, V. (2001, July). Hospice enrollment and hospitalization of dying nursing home patients. The American Journal of Medicine, 111(1), 38-44. PubMed https://doi.org/10.1016/S0002-9343(01)00747-1

33. Miller, S. C., Mor, V., Wu, N., Gozalo, P., \& Lapane, K. (2002, March). Does receipt of hospice care in nursing homes improve the management of pain at the end of life? Journal of the American Geriatrics Society, 50(3), 507-515. PubMed https://doi.org/10.1046/j.1532-5415.2002.50118.x

34. Shega, J., Hougham, G., Stocking, C., Cox, D., \& Sachs, G. (2008, May). Patients dying with dementia experience at the end of life and impact of hospice care. Pain symptom Manage, 5(5), 499. Doi 
35. Centers for Medicaid \& Medicare. (n.d.). Medicare hospice benefit: Early program experiences. Retrieved from: https://www.cms.gov/research-statistics-data-andsystems/research/healthcarefinancingreview/downloads/cms1192048dl.pdf

36. World Health Organization. (n.d.). Palliative care. Retrieved from: https://www.who.int/news-room/fact-sheets/detail/palliative-care

37. Siderow, S., \& Silvers, A. (n.d.) Alternative payment supports palliative care across the continuum. Retrieved from: https://www.media.capc.org

38. World Health Organization. (n.d.). Palliative care. Retrieved from: https://www.who.int

39. Lamont, E. B., \& Christakis, N. A. (2001, June 19). Prognostic disclosure to patients with cancer near the end of life. Annals of Internal Medicine, 134(12), 1096-1105. PubMed https://doi.org/10.7326/0003-4819-134-12-200106190-00009

40. White, D. B., Ernecoff, N., Buddadhumaruk, P., Hong, S., Weissfeld, L., Curtis, J. R., . . . Lo, B. (2016, May 17). Prevalence of and factors related to discordance about prognosis between physicians and surrogate decision makers of critically ill patients. JAMA, 315(19), 2086-2094. PubMed https://doi.org/10.1001/jama.2016.5351

41. Delaware Department of Health and Social Services. (n.d.). Are Delaware Medical Orders for Scope of Treatment (DMOST) different than advance directives? Retrieved from https://dhss.delaware.gov/dhss/dsaapd/dmost.html

42. Center to Advance Palliative Care. (n.d.). State by State report card for access to palliative care. Retrieved from: https://reportcard.capc.org/

Copyright (c) 2021 Delaware Academy of Medicine / Delaware Public Health Association.

This is an Open Access article distributed under the terms of the Creative Commons Attribution Non-Commercial License (https://creativecommons.org/licenses/by-nc-nd/4.0/) which permits unrestricted non-commercial use, distribution, and reproduction in any medium, provided the original work is properly cited. 